\title{
Functie en betekenis van de Management Letter voor ondernemingsbestuur en accountant
}

\section{Inleiding}

In Nederland is langzamerhand de praktijk ontstaan dat in navolging van onze Angelsaksische buren de openbare accountant naast de accountantsverklaring bij de jaarrekening en het accountantsrapport een Management Letter aan het bestuur van een onderneming afgeeft. De Nederlandse literatuur over de Management Letter is schaars ${ }^{1}$. In een onlangs verschenen NIvRA-brochure 'Accountant en Commissaris' wordt recentelijk weer eens op dit fenomeen gewezen ${ }^{2}$. Ook het zojuist verschenen Leerboek Accountantscontrole besteedt aandacht aan de Management Letter ${ }^{3}$. Gesteld wordt namelijk dat de accountant naast de accountantsverklaring in het kader van zijn algemene controle ook andere mededelingen dan verklaringen afgeeft. Deze hebben 'betrekking op onvolkomenheden of tekortkomingen die bij de uitvoering van de controle-opdracht zijn geconstateerd'. De Management Letter wordt daartoe als middel genoemd, waarbij erop wordt gewezen dat bij afsluiting van de controle over een zekere periode de in een brief vastgelegde opmerkingen aan de leiding van de huishouding ter kennis worden gebracht. 'In een overleg tussen de leiding en de accountant worden de opmerkingen besproken en worden maatregelen ter verbetering overwogen. In de volgende controleperiode gaat de accountant het effect ervan na'.

Het loont zeker de moeite om, nu meer en meer de Management Letter onder de aandacht van accountants en ondernemingsbesturen wordt gebracht, enkele opmerkingen over dat instrument te maken.

\section{Definitie en functie van de Management Letter}

Onder een Management Letter versta ik de schriftelijk door de accountant vastgelegde, voor de hoogste leiding van een huishouding bedoelde, opmerkingen van bijzondere aard inzake onvolkomenheden en tekortkomingen in de administratie en/of interne organisatie, de presentatie van de jaarrekening, de gang van zaken in de huishouding, de door de leiding van die huishouding gemaakte prognoses en de overige mededelingen in jaarverslag en/of tussentijdse berichtgeving.

De functie van de Management Letter is tweezijdig. Zowel voor de controlerend accountant als voor de leiding van de huishouding is het van betekenis, dat wordt vastgelegd tot welke opmerkingen de accountantscon- 
trole aanleiding geeft. De leiding zal door deze opmerkingen op onvolkomenheden, tekortkomingen en de voor de beleidsverantwoordelijkheid belangrijke zaken, welke zich in het verslagjaar hebben voorgedaan, worden geattendeerd. De accountant legt zijn verantwoordelijkheid vast, waardoor hij als het ware gedéchargeerd wordt voor de door hem verrichte werkzaamheden; daardoor kan hij de verantwoordelijkheid voor de door hem verrichte controle en de uitkomsten daarvan dragen. Bovendien geeft het hem een basis om de mate, waarin van zijn opmerkingen gebruik zal worden gemaakt achteraf te beoordelen.

\section{Uitwerking van de doelstelling van de Management Letter}

Het is niet de bedoeling dat de Management Letter een verslaglegging van de door de accountant verrichte werkzaamheden wordt. Terecht heeft Limperg er indertijd op gewezen dat het niet gaat in de verslaglegging van de accountant aan de leiding om een positieve takkeschrijving te geven, maar dat, waar het van materieel belang is, negatief zal moeten worden gerapporteerd, dat wil zeggen moet worden vermeld welke zaken de accountant niet in zijn controle kon betrekken ${ }^{4}$.

Evenmin is het de bedoeling van de Management Letter dat de accountant daarin een evaluatie pleegt van de positieve en negatieve aspecten van de interne organisatie of de interne controle. Het doel moet zijn het aangeven van belangrijke onvolkomenheden en tekortkomingen, die weliswaar niet hebben geleid tot het geven van een afkeurende verklaring of een verklaring van oordeelonthouding, maar die toch dienen te leiden tot maatregelen ter verbetering van de organisatie.

Voor het geval de accountant een oordeelonthouding of een afkeurende verklaring had moeten geven bij de jaarrekening zal uiteraard ook het accountantsrapport de motivering daarvan kunnen en moeten geven.

Opgemerkt moet worden dat de Management Letter mede kan dienen voor het vastleggen van afspraken, die over de jaarrekeningpresentatie of over de kwaliteit van de interne organisatie en interne controle met de leiding zijn gemaakt vóórdat de accountantsverklaring bij de jaarrekening werd afgegeven. Het is namelijk zeer goed denkbaar dat de accountant een goedkeurende verklaring geeft maar dat hij een aantal voorwaarden heeft gesteld dat moet zijn vervuld, wil hij in de toekomst nog een goedkeurende verklaring als haalbaar zien. Uiteraard betreft dit niet een geval waarbij de goedkeuring als het ware wordt geconditioneerd, maar gaat het erom te waarschuwen voor continuering van bepaalde onbevredigende situaties, die tenslotte de door de accountant gegeven goedkeuring kunnen aantasten. Voor wat betreft een paragraaf in de Management Letter over de jaarrekeningpresentatie en -interpretatie kunnen opmerkingen van de accountant betrekking hebben op ontwikkelingen hierin die hem zorgen baren. Om enkele voorbeelden te noemen:

- de financiële structuur van de onderneming kan zorgelijk zijn of binnen afzienbare tijd worden (solvabiliteitsaspecten); 
- de gemiddelde debiteurentermijn kan bovenmatig zijn opgelopen (liquiditeitsaspecten);

- de voorraden kunnen in verhouding tot de omzetten onrustbarend zijn gestegen (liquiditeitsaspecten);

- de termijn, waarop leveranciers worden betaald kan te lang zijn geworden (idem);

- de netto resultaten kunnen zodanig zijn gepresenteerd dat incidentele posten, of onevenredig grote of kleine belastingverplichtingen het beeld van de werkelijke rentabiliteit hebben vertekend (presentatie-aspecten);

- toename van de risico's die de onderneming loopt door valutaposities, oplopende garantieverplichtingen en dergelijke;

- gebreken van betekenis in de geautomatiseerde informatieverwerking.

Maar ook over zaken, die zonder dat deze aanleiding tot enige zorg geven, voor het beleid en de oordeelsvorming van de leiding van betekenis zijn, kan de Management Letter informatie geven die van voldoende betekenis is om vastgelegd te worden, zoals opmerkingen over belangrijke gebeurtenissen nả balansdatum (en de reden waarom deze wel of niet in de jaarrekening zijn verwerkt), opmerkingen over latente of acute belastingverplichtingen, enz.

Alhoewel aangenomen mag worden dat in vele gevallen, onder meer doordat de leiding van balansverhoudingen en resultatencijfers periodiek, bijv. in de vorm van kengetallen, kennisneemt, reeds voldoende inzicht is verkregen in de gememoreerde ontwikkelingen, is de accountant niet van zijn verantwoordelijkheid ontslagen indien hij niet de belangrijkste afwijkingen in de ontwikkelingen binnen de onderneming en/of in de presentatie van de jaarrekening aan de leiding voorlegt, periodiek en na afsluiting van zijn controle in de Management Letter. Datzelfde moet worden gezegd van opmerkingen over de kwaliteit van de interne organisatie.

\section{Verschil en overeenkomst tussen accountantsrapport en Management Letter}

Het accountantsrapport heeft als doelstelling het geven van een toelichting door de accountant op de door hem gecertificeerde jaarrekening. Daarnaast is het te beschouwen als het door de wet ex artikel 393, lid 4 BW 2 vereiste verslag, dat de accountant omtrent zijn onderzoek aan de Raad van Commissarissen en het Bestuur moet uitbrengen.

Men zal zich nu afvragen of en waarom ook de onder 3 genoemde onderwerpen niet bij uitsluiting in het accountantsrapport kunnen of moeten worden besproken. Naar mijn mening valt hiervoor geen algemene regel te geven. Er zijn wel enkele nadelen verbonden aan het bij uitsluiting hanteren van het accountantsrapport voor het maken van opmerkingen over onvolkomenheden en tekortkomingen in de jaarrekening, organisatie, en dergelijke van de huishouding. Daarbij zal men zich moeten realiseren dat zowel voor kleine als grote ondernemingen bezwaren kunnen rijzen indien de accountant in het accountantsrapport bij de jaarrekening van de onderneming tevens de in de vorige paragraaf bedoelde kritische opmerkingen 
vastlegt. Het accountantsrapport zal namelijk een eigen leven kunnen gaan leiden. Dat betekent dat het niet slechts ter kennis zal komen van de hoogste leiding en de toezichthouders daarop (hier verder te noemen Raad van Bestuur en Raad van Commissarissen), maar dat het tevens in bijzondere gevallen ter tafel komt bij derden. Te denken valt aan fusies, overnamen, en dergelijke waarbij aan de fusionerende of overnemende partij het accountantsrapport zal moeten worden overgelegd, en voorts aan gevallen als onderhandelingen met betrekking tot het verkrijgen van bankkredieten, waarbij aan de bankiers het accountantsrapport moet worden verstrekt. Ook is het mogelijk dat, ingeval van voorgenomen emissies, het accountantsrapport aan de bank of banken ter kennis moet worden gebracht. Samenvattend kan het voor een onderneming schadelijk zijn, vooral bij eerste onderhandelingen, als meteen in volle omvang een aantal tekortkomingen en gebreken via het accountantsrapport moet worden opengelegd. Het is niet ondenkbaar dat voorgenomen fusies, overnamen, kredietaanvragen of emissies niet doorgaan. In dat geval zou, indien reeds het accountantsrapport met daarin opgenomen kritische opmerkingen ter inzage was verstrekt, onnodig teveel aan informatie zijn prijsgegeven.

Dit betekent niet, dat ik een pleidooi houd voor het ontzeggen van voor het inzicht benodigde informatie aan derden. Het is echter een kwestie van fasering, met andere woorden van de vraag op welk tijdstip het dienstig is dat informatie wordt verstrekt en welke informatie voor dát tijdstip adequaat moet worden geacht. Een afzonderlijke Management Letter, waarin breder en dieper op onvolkomenheden en tekortkomingen wordt ingegaan maakt de fasering als het ware mogelijk.

Een en ander betekent evenmin, dat opmerkingen die in een Management Letter worden gemaakt niet in het accountantsrapport kunnen of mogen voorkomen. Het accountantsrapport zal echter in het algemeen - een en ander afhankelijk van de aard en grootte van de huishouding, de samenstelling van het bestuur enz. - op cijfermatige opstellingen en uiteenzettingen daarbij zijn geconcentreerd. Het blijft uiteraard mogelijk om in rudimentaire vorm reeds in het accountantsrapport te wijzen op zaken die in de Management Letter nader worden uitgewerkt. In dat geval vermijdt men echter niet dat in bijzondere gevallen wellicht ongewenst informatie aan niet-ingewijden of derden wordt gegeven, die beter achterwege had kunnen blijven.

Tenslotte moet erop worden gewezen dat de uiteenzettingen in de Management Letter in geen geval de strekking van een afgegeven goedkeurende verklaring kunnen aantasten. De accountant mag niet in de Management Letter terugnemen hetgeen hij impliciet met zijn goedkeurende verklaring bij de jaarrekening heeft bedoeld te geven. De Management Letter is niet te beschouwen als een clausule bij de goedkeurende accountantsverklaring. Datzelfde geldt overigens ook voor het accountantsrapport dat naast een (al of niet gepubliceerde) goedkeurende accountantsverklaring wordt uitgebracht. 


\section{Procedures bij de opstelling van de Management Letter}

De procedure die moet leiden tot het opstellen en uitbrengen van de Management Letter is op zichzelf eenvoudig. In de loop van het jaar worden door de openbare accountant bij zijn algemene controle opmerkingen over onvolkomenheden en tekortkomingen in verslaglegging en organisatie vastgelegd; periodiek worden deze met de leiding op diverse échelons besproken. Aan het eind van de jaarcontrole worden de belangrijkste opmerkingen verzameld en gevoegd bij die, welke over de jaarrekeningpresentatie zijn te maken. Tezamen worden deze in een concept-Management Letter vastgelegd. Daarna worden de diverse paragrafen van de concept-Management Letter met de voor die onderdelen verantwoordelijke functionarissen doorgenomen, waarna de concept-Management Letter aan de leiding (i.c. Raad van Bestuur) wordt gepresenteerd als discussiestuk.

Indien de leiding akkoord gaat met de formulering en de inhoud van het concept, en na het aanbrengen van wijzigingen op grond van de discussie, wordt de definitieve Management Letter uitgebracht. Deze wordt dan voorgelegd aan de Raad van Bestuur en de uiteindelijke opdrachtgever van de openbare accountant, te weten de Raad van Commissarissen. Uiteraard kunnen ook de concepten tegelijkertijd naar Raad van Bestuur en Raad van Commissarissen gaan. Dat is een kwestie van bedrijfsbeleid.

De vraag kan hier worden gesteld of de Management Letter eigenlijk wel aan de Raad van Commissarissen dient te worden uitgebracht. De toezichthouder maakt immers geen deel uit van het management, indien althans dit in enge zin wordt opgevat. Daartegenover moet worden opgemerkt dat de Raad van Commissarissen ex artikel 140, lid 2 en artikel 250, lid 2 BW 2 tot taak heeft het houden van toezicht op het beleid van het Bestuur en op de algemene gang van zaken. Dit houdt in dat het kennen van alle op de organisatie van de vennootschap betrekking hebbende problemen, voorzover van gewicht, voor zijn functie van toezichthouder van belang is. Dit zou weer pleiten voor het verstrekken van de Management Letter aan de Raad van Commissarissen. Voor het verdere betoog houd ik het erop dat de Management Letter aan de Raad van Commissarissen wordt voorgelegd. De praktijk zal uiteraard van vennootschap tot vennootschap kunnen verschillen.

Nadat in een pleno-vergadering (Raad van Bestuur plus Raad van Commissarissen), bij voorkeur in aanwezigheid van de openbare accountant, de Management Letter is besproken, worden de maatregelen ter verbetering van bepaalde tekortkomingen en ter voorkoming van bepaalde misstanden vastgesteld en te gelegener tijd besproken met de subalterne leiding.

Het hier voorgestelde schema kent natuurlijk allerlei variaties. Zo is het mogelijk dat de leiding eerst zélf met de subalterne leiding de Management Letter bespreekt en als vervolg daarop een antwoord voor de accountant opstelt. Daarna zou de Management Letter met het commentaar van de hoogste leiding in het bijzijn van de toezichthouder, i.c. Raad van Commissarissen, kunnen worden besproken. Het is duidelijk dat een Audit Committee bij de behandeling van de Management Letter een belangrijke rol 
kan vervullen, zelfs orgaan bij uitstek is om een dergelijk document te bespreken.

\section{De interne accountant en de Management Letter}

Het is hier de plaats om iets te zeggen over de rol van de interne accountant bij de samenstelling van de Management Letter. In de praktijk komt het namelijk voor, dat de Management Letter wordt geschreven door interne en externe accountants gezamenlijk en ondertekend wordt door interne en externe accountant. De vraag kan hier worden gesteld of het doelmatig is dat de Management Letter door interne èn externe accountant gezamenlijk wordt opgesteld.

Aan het antwoord op deze vraag zitten verschillende nuances. Een voordeel bij het opstellen van de Management Letter door beide instanties is, dat bij een grote onderneming (en alleen dảár fungeren interne accountants) door beiden, zowel interne als externe accountant, bij de controle kennis wordt genomen van onvolkomenheden en tekortkomingen in organisatie en jaarrekeningpresentatie. Door de interne accountant wordt daar, als het goed is, reeds periodiek aan subalterne maar in vele gevallen ook aan de opperste leiding gerapporteerd. Waar bovendien de interne accountant dichter bij het bedrijfsgebeuren zit en dus meer oog zal hebben voor het bedrijfsgebeuren, is het bijna onvermijdelijk dat hij in de opstelling van de Management Letter een belangrijke rol kan en moet spelen. Het meest doelmatig is het dan ook dat beiden hun krachten bundelen en gezamenlijk rapporteren.

Als nadeel zou kunnen worden aangevoerd dat in gezamenlijke rapportage opmerkingen worden gemaakt over situaties, die door het optreden van de interne accountant binnen een periode van de controle reeds zouden moeten zijn waargenomen en waarover door hem reeds zal zijn gerapporteerd. Dit lijkt mij echter op zichzelf geen bezwaar. De interne accountant staat in ieder geval buiten het bedrijfsbeleid en kan slechts adviezen verstrekken of meningen uiten over geconstateerde feilen in de organisatie. De herhaalde rapportage daarover, de belangrijkste, reeds door de interne accountant aangedragen opmerkingen door interne en externe accountant gezamenlijk in de Management Letter verwoord, kunnen in gemoede niet zo worden uitgelegd, dat de Management Letter uiteindelijk een veroordeling inhoudt over gebrek aan advieskracht of overtuigingskracht van de interne accountant. Ook de kwalitatief meest hoogstaande interne accountantsdienst zal niet kunnen voorkomen dat er in een onderneming van enige omvang bepaalde onvolkomenheden optreden en met zijn opmerkingen daarover nog niet uit de weg zijn geruimd. Wél kan als schijnbaar bezwaar tegen samenwerking van interne en externe accountant met betrekking tot de Management Letter worden aangevoerd, dat de externe accountant op situaties kan stuiten die het functioneren van de hoogste leiding betreffen en die tot kritische opmerkingen over de kwaliteit van die leiding zouden kunnen leiden. Het gaat dan niet aan dat de interne accountant mede rapporteert over handelingen van de hoogste leiding, die tot kritiek aanlei- 
ding geven, omdat de interne accountant functioneel aan die leiding ondergeschikt is. Dit bezwaar behoeft niet reëel te zijn. Indien in de praktijk interne en externe accountant gezamenlijk de Management Letter samenstellen, zal in een geval als vorengenoemd de externe accountant zijn toevlucht moeten nemen tot het schrijven van een afzonderlijk stuk, dat náást de Management Letter aan toezichthouder en hoogste leiding wordt verstrekt (men zou kunnen zeggen een Management Letter-II) en dat ook niet ter kennis van de interne accountant behoeft te komen. Gevallen als deze laten zich echter als academisch en hoogstens uiterst zeldzaam denken.

\section{Eisen te stellen aan een Management Letter}

Tenslotte moeten nog enkele opmerkingen worden gemaakt over de eisen welke aan het opstellen en het verstrekken van een Management Letter moeten worden gesteld. Allereerst moet worden opgemerkt dat de Management Letter zijn kracht moet ontlenen aan de beknoptheid en belangrijkheid van de inhoud. Alleen werkelijk belangrijke zaken moeten in de Management Letter worden vermeld. Dat betekent dat toelichtingen op jaarrekeningposten en analyses van balansverhoudingen in het algemeen in het accountantsrapport moeten worden ondergebracht en niet in de $\mathrm{Ma}$ nagement Letter. De Management Letter dient vanuit de optiek van beleidsondersteuning te worden geschreven. De leiding 'moet er iets mee kunnen doen'. Van die zaken, die inmiddels tot een oplossing zijn gebracht, maar waarvan de leiding toch nog - mede gezien de eigen verantwoordelijkheid van de openbare accountant - in kennis moet worden gesteld, moet worden aangegeven, dat inmiddels verbetering is ingetreden. Deze moeten duidelijk worden onderscheiden van zaken waarbij een ingreep van de hoogste leiding wordt verwacht. Dat kunnen gevallen zijn van beduidende verslechtering, die optreedt in de interne organisatie, gevallen waarbij verantwoordelijkheden en bevoegdheden niet afdoende of in het geheel niet zijn geregeld, ernstige risico's in structuur of in handelwijze van de onderneming, risico's die het voortbestaan van het bedrijf of delen daarvan bedreigen, enz. Gevallen die misschien in de toekomst ook het afgeven van een goedkeurende verklaring in de weg kunnen staan.

Het spreekt vanzelf dat er een goede 'follow-up' zal moeten zijn. Ik heb daar reeds bij de paragraaf over de procedures op gewezen. De accountant zal echter jaarlijks dienen vast te stellen dat de in de voorgaande Management Letter opgesomde gebreken en tekortkomingen zijn opgenomen door de leiding en behandeld met het bedrijf respectievelijk, wanneer dit niet het geval is, dat men in ieder geval met maatregelen in dat opzicht bezig is. Indien bepaalde zaken uit een voorgaande Management Letter bevredigend zijn geregeld, kan het ook geen kwaad, dat dit duidelijk wordt uitgesproken in de nieuw te schrijven Management Letter.

En dan nog dit: de opstellers van de Management Letter moeten geen belerend of docerend verhaal schrijven! 
Samengevat zijn de te stellen eisen dus:

- beknoptheid en duidelijkheid;

- alle materieel belangrijke zaken aan de orde stellen;

- aangeven wanneer de leiding moet ingrijpen;

- in elke Management Letter vaststellen of de in voorgaande Management Letter genoemde problemen zijn opgelost;

- alle schijn dat er wordt gedoceerd, vermijden.

\section{Beoordeling van het geautomatiseerde informatiesysteem en de Management Letter}

In het voorgaande is ervan uitgegaan dat de accountant een accountantsverklaring afgeeft, daarnaast een accountantsrapport opstelt en tenslotte periodiek, stel jaarlijks, een Management Letter aan de leiding geeft waarin, als gezegd, onvolkomenheden en tekortkomingen in de organisatie naast presentatievraagstukken worden besproken. De mogelijkheid bestaat dat ten behoeve van de leiding of van derden door de accountant ook mededelingen worden gedaan over de betrouwbaarheid en de continuiteit van de geautomatiseerde gegevensverwerking.

Op de mogelijkheid dat de accountant aparte mededelingen verstrekt over dit onderwerp en over de zinnigheid daarvan wordt hier niet verder ingegaan. Ik verwijs hiervoor naar het NIvRA-geschrift over 'Automatisering en controle', met name deel IV, waarin deze problematiek wordt behandeld. Wel moet worden opgemerkt dat de accountant in het kader van zijn controle-opdracht dan wel bij het verrichten van een wat gerichter systeemonderzoek over het informatiesysteem in het algemeen wel tot een oordeel zal komen over de betrouwbaarheid en continuiteit van het geautomatiseerde informatiesysteem. Dat laatste zou in een aparte mededeling kunnen worden neergelegd ${ }^{5}$.

Echter moet stelling worden genomen tegen de in het genoemde geschrift neergelegde opvatting, 'dat eventuele afwijkingen van de door de accountant aangelegde normen, die het oordeel niet aantasten en dus niet in de mededeling behoeven te worden opgenomen, kunnen toch ter kennis van de opdrachtgever worden gebracht en wel in een begeleidend schrijven bij de mededeling ('Management Letter')'6.

Hier wordt de indruk gewekt dat de Management Letter, naast een specifieke mededeling als 'begeleidend schrijven' bij die mededeling wordt gehanteerd. Dat is de zaak omdraaien. De Management Letter is niet 'begeleidend' in de zin dat deze naast specifieke uitkomsten van een (automatiserings-)onderzoek wordt verstrekt. Het is een zelfstandig stuk, dat natuurlijk wél in een daartoe opgestelde paragraaf kan wijzen op een apart verrichte (i.c. automatiserings-)opdracht. 


\section{Conclusies}

Als conclusie uit de voorgaande beschouwingen kan worden opgemerkt dat de Management Letter langzamerhand een document is geworden dat zich niet meer laat wegdenken in de verhouding tussen accountant en opdrachtgever, te weten de hoogste leiding van een huishouding en de toezichthouder op die leiding. Voor zowel de openbare als de interne accountant is de Management Letter, naast vastlegging van eigen verantwoordelijkheid, tevens een middel om beleidsondersteunend werkzaam te zijn. Voor de ondernemingsleiding is het een vastlegging van belangrijke feilen en tekortkomingen in de gang van zaken, die kan dienen ter bepaling en ondersteuning van het beleid. Voor de toezichthouder kan het bovendien een instrument zijn dat inzicht geeft in de kwaliteit van de organisatie van de huishouding; daardoor zal ook de toezichthouder zich bij zijn verantwoordelijke taak gesteund kunnen weten.

Tenslotte is de Management Letter ook een geschrift dat als basis kan dienen - en als het goed is ook zăl dienen - voor overleg tussen de Raad van Bestuur, de Raad van Commissarissen, de externe en de interne accountant. Of dat in een Audit Committee (met deelname van enkele leden uit genoemde organen) of in een gremium bestaande uit de gehele Raad van Bestuur en Raad van Commissarissen geschiedt, is van minder belang. Als het overleg maar periodiek plaatsvindt.

Noten

1 Zie J. M. Vecht, 'Betekenis van de Management Letter voor de accountant' in Handboek Accountancy, I.220 en Th. Malais, 'Management Letters', De Accountant, 1978, nr. 7, blz. 394 e.u Voorts lemma 'Management Letter' in de Encyclopedie van de Bedrijfseconomie, $3 e$ ed., 1984, pag. 1266/1267.

2 'Accountant en Commissaris, Nazien en toezien', NIuRA 1985, pag. 14 e.u.

3 'Leerboek Accountantscontrole', hfdst. 2.3.520, pag. 78.

4 Bedrijfseconomie, Verzameld werk van Prof. dr Th. Limperg Jr., deel VI, Deventer 1965, pag. 219: 'En in dezelfde geest wordt ook niet de opsomming van de verrichte werkzaamheden vereist, doch de opsomming van al hetgeen de accountant heeft nagelaten of heeft moeten nalaten van al hetgeen nodig is om het onderzoek en dus ook de verklaring volkomen te maken, overeenkomstig het doel van het onderzoek en de specifieke functie'.

5 Mededeling, geen verklaring! Het betreft hier namelijk geen uitkomst van een onderzoek naar de getrouwheid van een verantwoording.

6 Zie NIURA-geschrift 26, getiteld 'Automatisering en controle', deel IV, Mededelingen door de accountant met betrekking tot de betrouwbaarheid en continuiteit van geautomatiseerde gegevensverwerking, febr. 1982, Kluwer/Deventer, pag. 24. 